\title{
Antagonismo como mediación comunicativa que politiza la acción
}

El antagonismo para Laclau y (2004) es imprescindible, porque hace evidentes los límites que estructuran lo social, al develar las diferencias de sentido e identidad que se vinculan intersubjetivamente en el entramado de las relaciones sociales, como campo discursivo y de la acción. El antagonismo posibilita hacer evidentes los límites establecidos a partir de dichas diferencias, con el fin de desbordarlos o modificarlos; esta es su potencia, que se configura como una posibilidad de enunciación que engendra acción instalando en el imaginario y en el mundo de la vida una opción de ruptura y modificación que se produce contingentemente.

Los agentes están inmersos en diversas formaciones discursivas a partir de las posiciones de sujeto que ocupan de forma plural y contextual (Mouffe, 1999). Esto hace que el antagonismo se haga presente en las diversas redes de socialización en las que los agentes están vinculados, y modifica así permanentemente las identidades, lo que supera el supuesto de entidad fija u homogénea que generalmente se les atribuye y, por ende, afecta también la idea de lo social como un sistema cerrado. Esto deja en evidencia que la condición de objetividad que se le otorga a lo social es una condición precaria que nunca se establece definitivamente y que se muestra como tal justamente cuando se develan los límites de lo social. 
El asunto es cómo hacer del antagonismo una fuente de lo político, desde el ámbito discursivo pero también en la práctica, es decir, en el discurso y la acción, en el sentido arendtiano. Para esto, hay que propender hacia un antagonismo en términos comunicativos, es decir, como una interacción dotada de sentido que es altamente productiva al configurar relaciones sociales que movilizan no solo actores sino sobre todo significaciones, a partir de las cuales se establece lo social como entidad dinámica e inacabada.

Como vimos, la relación amigo/enemigo que hizo célebre a Schmith es limitada para pensar un antagonismo comunicativo en el sentido que acá se busca, es decir, suponer que solo en esa perspectiva se pueden proyectar las interacciones humanas es demasiado restringido. En tanto, la dicotomía amigo/enemigo no permite tramitar dicha interacción, y si hay algo que caracteriza a los humanos es justamente la diversidad de posiciones de sujeto o configuraciones significativas que se gestan permanentemente en las relaciones sociales que no se limitan únicamente a esta condición excluyente.

Siguiendo a Laclau y Mouffe (2004), el antagonismo permite a los agentes de los procesos comunicativos identificar-se en dicha interacción, es decir, establecer líneas o repertorios de acción a partir de la sintonía o disidencia que establecen en las relaciones de interacción. Esta es una operación que se despliega permanentemente en todos los vínculos sociales, establecer posturas en la diferenciación yo/él, nosotros/ellos, o sea, trazar límites y características que diferencian a los agentes, que establecen singularidades, pero que también implican coincidencias o diferencias radicales. Así, el antagonismo es un ejercicio comunicativo que define roles, establece vínculos diferenciales entre los agentes y es altamente productivo en el ámbito de lo público, en el sentido de que inaugura otras posibilidades de actuación en torno a esa relación. Para esto, es necesario tener presente el reconocimiento de la diferencia, sin que esto necesariamente implique confrontación o conflicto, como una apertura hacia un campo inédito de relación que está por construirse, que puede terminar en oposición, en negociación, en conflicto o simplemente no puede pasar nada más allá de servir como dispositivo que devela esa apertura comunicativa, 
porque su gestión o trámite dependen de los actores, de los intereses y de las circunstancias implícitas en dicha interacción.

Pero no es solo eso. Al efectuarse dicho reconocimiento, es necesario un proceso de "construcción" del antagonismo, como una práctica reflexiva por lo menos por una de las partes, que define o establece cómo configurar el intercambio, los contenidos o el tipo de vínculos que se establecerán a futuro en función de los intereses en juego, de las posiciones o roles que desempeñan los agentes; en últimas, es una apertura reflexiva para dotar de sentido esa interacción a partir de lugares contingentes e inéditos de vinculación.

Por ejemplo, en las experiencias consultadas, cada uno de los grupos identifica por lo menos un antagonismo que motiva su acción estética. Dicha condición no implica necesariamente reciprocidad o correspondencia de oposición en una interacción con un agente específico, sino más bien frente a un imaginario social, a una condición territorial particular o a unas prácticas específicas. En estos casos, los antagonismos son diferentes y llevan a estos jóvenes a reelaborar sus perspectivas para reconocerse como agentes activos en dicha relación, dotados de acción y palabra a partir de la cual pueden resignificar para sí, para el grupo y su entorno inmediato el sentido que le otorgan a dicha fuerza antagónica, la cual se hace manifiesta o es expresada en experiencias estéticas.

En el caso de los teatreros por la paz, su apuesta estética se erige en oposición a la violencia, a los actos que destrozan el tejido social tumaqueño. Acá no podemos identificar a un actor concreto que represente la fuerza de la violencia en esta comunidad, ${ }^{7}$ pero todo el andamiaje que alimenta los montajes responde a una oposición específica a naturalizar los estragos de la violencia en el interior de la comunidad. Así, su trabajo se nutre de dicho antagonismo, asumido

7 ¿Quiénes son los actores violentos en Tumaco? Según los informes anuales de la Diócesis, en este sector del país se reconocen acciones de grupos paramilitares, guerrilleros de las Fuerzas Armadas Revolucionarias de Colombia (FARC) y del Ejército de Liberación Nacional (ELN), que se disputan el control territorial y su participación en negocios ilícitos, lo cual aumenta la presencia de Ejército Nacional, la Marina y la Policía. 
como oposición sin “sujeto", por decirlo de alguna manera, pero que es visible y que le permite al grupo desplegar una serie de elementos estéticos y simbólicos para tramitar dicha oposición. Esta última se puede identificar como resistencia, denuncia o visibilización de casos concretos que permiten resignificar o reelaborar en términos de significación dicha relación, para producir otras posibilidades de sentido, instaurar otros contenidos, otras prácticas en relación con la violencia y la vida.

Puntualmente buscan oponerse a las condiciones de silencio y de miedo que produce la violencia en esta zona del país. Expresarse, denunciar, profundizar y visibilizar el sentir de las víctimas es una práctica cada vez menos frecuente en contextos donde la violencia produce complejas formas de miedo y terror en la gente, que fracturan el tejido social e impiden la posibilidad de organización comunitaria. El teatro, como una forma privilegiada de expresión, permite justamente eso: denunciar, visibilizar, generar reflexión y conversación en torno a la situación que experimentan los tumaqueños, mostrar las transformaciones culturales, sociales y políticas a las que se han visto sometidos arbitrariamente:

En Tumaco fue de un tiempo para acá que empezó la violencia, porque a cualquiera que usted le pregunte en el municipio le va a decir que antes se salía a cualquier hora de la tarde, de la noche, y no le pasaba nada, podía hacer rumbas afuera de su casa, caminar, los niños antes jugaban hasta tarde en la noche, y después de un tiempo, luego de las nueve no se podía salir de la casa, no se podía ver a nadie por fuera porque lo mataban, escribían panfletos y siempre había ese temor, y todos los días amanecían muertos y bueno, no vamos a decir que estamos en un buen momento, pero sí ha mejorado, ésta es la época menos tensa después de unos años. (Zulma, 10 de mayo de 2014, entrevistada por Molina, I., Tumaco)

Justamente, las obras de teatro se oponen a permitir que la violencia continúe deteriorando las relaciones sociales, minando la confianza y obligando a los tumaqueños a vivir con miedo y a olvidar su origen, sus prácticas colectivas y ancestrales. Además, le apuestan a pensar 
que las víctimas no solo son aquellas personas a quienes se les asesina un familiar, sino también las comunidades en su interior, y la gran víctima es la sociedad en general.

Más allá de que yo sea víctima directa o de que tocaron a uno de los míos, es como ese dolor de pueblo, dolor de tierra, ver que es toda una comunidad la que se ve afectada es ver cómo se van deteriorando o acabando las costumbres que han tenido nuestros pueblos porque por el miedo ya la gente no va a un velorio, por el miedo la gente no celebra sus fiestas como lo celebraban antes, ese estado de zozobra, de miedo, eso que uno vea la violencia como normal, tu rompes con todos esos pensamientos erróneos pero que uno se va acostumbrando tanto que ya lo ves como tan normal, ya uno logra fijarse de lo que está pasando así no me toque directamente es una cosa que nos hace daño, pero ya uno rompe con esa indiferencia y se vuelve más sensible con el dolor del otro, y va creando esa sensibilidad de no ver y no acostumbrarse a verlo como normal, por un lado, y por otro lado, uno aprende a ser un poco más tolerante. (Karen, 15 de mayo de 2014, entrevistada por Molina, I., Tumaco)

El interés de Teatro por la paz es justamente instalar discursivamente y simbólicamente a través de sus obras una reflexión frente al dolor que produce la violencia, frente a cómo las prácticas de los violentos han transformado las costumbres de la ciudad, cómo se rompen las tradiciones ancestrales y cómo se fracturan los lazos de confianza, cooperación y reciprocidad a raíz del miedo y qué consecuencias o prácticas privilegian estos hechos, tanto en la comunidad en general, como también en el interior de las familias y en la subjetividad de las víctimas.

En una ciudad donde el silencio y el miedo se convierten en una constante de la vida pública; el interés por manifestar las discrepancias y resistir creativamente a los actos de violencia se vuelve un hecho significativo para tratar de hacer de la vida pública un espacio de expresión y de manifestación frente al contexto. Llama la atención que la transformación de sentido también afecte el imaginario vinculado a la condición juvenil, pues para ellos y para su comunidad es claro 
que el trabajo que adelantan estos jóvenes que están en proceso de formación, y que aparentemente no tienen aún un juego decisivo en el campo de lo social, dadas sus condiciones de edad y escolaridad, es vital para resignificar el hecho de ser víctima y de hacer parte de una ciudad como Tumaco.

Como resultado de ese antagonismo vigente, estos jóvenes han logrado consolidarse como grupo, se han hecho visibles y han logrado convertir su apuesta estética en un ámbito de enunciación que afecta a los espectadores de estos montajes, manifestándose a través del teatro y del ejercicio de mímesis, en contra de la violencia y el atropello a los derechos humanos.

Por otro lado, Uno entre mil se configura en oposición a la vida cotidiana dominada por una lógica de globalización moderna con sus afanes, al consumo en exceso, a la educación atrapada, a la carrera del tiempo que no permite vivir feliz, a esa forma de vivir tan encapsulada en tiempos fugaces, en ausencia de espacios para el juego, el disfrute y la sustitución material de esta necesidad humana.

El caos es todo ese tema del consumismo, es todo eso que hay en el afuera, la institucionalidad, la educación atrapada, el academicismo que a veces uno no sabe pá dónde lo lleva a uno. Uno para poder ser bueno en algo no sólo tiene que ser profesional sino también especialista, tiene que ser magister y después doctor porque si no nadie lo respeta, entonces nos hemos convertido en profesionales analfabetas porque si no nos especializamos no sabemos, no estamos donde deberíamos estar, todo esto nos mete en una carrera loca y cuál es la carrera loca, a que usted consuma, consuma educación, consuma servicios, a que usted todo el tiempo esté consumiendo consumiendo, y usted va en una carrera loca, y hay que hacerlo, y hay que sacarlo, y entonces tengo que conseguir casa, carro, beca y ya, porque si eso yo no soy nada, ni soy nadie. (Diana, 29 de marzo de 2014, entrevistada por Molina, I., Medellín)

Esta carrera de velocidades cada vez más altas llevó a los participantes de Uno entre mil a entender que la mayoría de los humanos es presa 
de un círculo vicioso que se apodera de la subjetividad y que impide la realización consciente de aquello que da sentido a la existencia singular.

\begin{abstract}
Nacho está esoterizado en esa realidad circular, atrapado, porque entre más uno hace, más se desgasta, más se cansa, porque sabe que está metido en una cosa que sabe que no es pero bueno, cada vez tiene menos tiempo para usted, cada vez menos feliz; entonces, de vez en cuando hay una persona que dice hey, un momentico, entonces para, y cuando para, ingresa a uno entre mil, y entonces dice: ¡Yo quiero hacer otra cosa! (Diana, 29 de marzo de 2014, entrevistada por Molina, I., Medellín)
\end{abstract}

Haciendo esa reflexión y esa parada a pensar-se es como algunos deciden entrar a hacer parte de la realidad de Uno entre mil, tratando de liberarse de aquellas formas sutiles que determinan todos los aspectos de la vida humana en la actualidad, y que privilegian ciertos valores sobre otros; por ejemplo, a ponerle un valor en términos de dinero a su tiempo, a la vida en general, a solo pensar en una estabilidad económica a costa de sus sueños, de sus deseos, de lo que realmente le interesa como persona. Esta es una manifestación concreta de cómo el juego se configura como antagonismo frente a este tiempo sin tiempo, al tiempo vacío que impera en la sociedad y a los imaginarios sociales que modelan las subjetividades humanas.

Para los Benjamines de Uno entre mil la realidad no la determina nadie, no le corresponde a nadie diferente que a uno mismo. Este es el paso que configura a un iniciado en el camino del Benjamín: que hace lo que quiere, lo que siente, no lo que le toca. "La realidad la creo yo, ya, es eso, no me la determina nadie, ni un banco, ni un amigo, ni un abuelo, ni la televisión, sólo por decidir entrar a un camino, y lo mejor aún, el camino lo creamos nosotros, o más que crearlo, lo develamos nosotros" (Uno entre Mil, 29 de marzo de 2014, entrevistados por Molina, I., Medellín).

Este antagonismo que moviliza al grupo se puede entender como una oposición concreta hacia la modernidad, a todos los elementos que la caracterizan: la importancia de la noción del tiempo y su velocidad, 
que limita el tiempo del ocio y el disfrute; la preeminencia al interés económico de subsistir y no de cualquier manera, sino atendiendo a las reglas del consumo exacerbado, a la necesidad de responder a unas lógicas productivas que privilegian el desempeño económico a costa de la tranquilidad emocional y a aumentar el uso irracional de los recursos naturales, ignorando la importancia de equilibrar el consumo y el cuidado en la relación entre hombre y naturaleza.

Para estos jóvenes que han reflexionado sobre su vida y su rol en los entornos a los que se vinculan, el hacer parte de este grupo les permite expresar e incorporar a su cotidianidad formas alternativas de oponerse a la lógica imperante de la modernidad. Si bien es un ejercicio que los obliga a pensar creativamente cómo resignificar el sentido de su trabajo, de sus prácticas de consumo, de sus formas de relación con los demás y muchas más variables, es colectivamente como van encontrando elementos para ocuparse de sí mismos como agentes de cambio y transformación en sus entornos inmediatos de acción.

Finalmente, para la gente de la Corporación Pasolini en Medellín, el trabajo que proponen es repensar o conocer a profundidad versiones de la cotidianidad, de la vida de los que viven en la ciudad, de los relatos propios, y por ende únicos. "En la base si es una cosa por lo cotidiano, lo pequeñito y trazar márgenes muy pequeñitas” (Germán y Wicho, 24 de marzo de 2014, entrevistada por Molina, I., Medellín). Ese trazar márgenes muy pequeñitas tiene que ver con la definición o con la posibilidad de nombrar límites, de mostrar fronteras desde donde se han establecido los relatos sobre lo urbano, sobre las identidades, y cómo esas fronteras no son fijas, sino que se sobrepasan, se reconfiguran en los relatos, en las vivencias y en las miradas que sobre estos producen sus protagonistas.

De ahí la importancia del proceso, pues estos contenidos son fruto de una creación colectiva, de una reflexión sobre la vida misma desde los protagonistas, procurando complejizar la mirada y evitar una mirada polarizada de bueno o malo frente a la realidad expuesta, pero si con un pensamiento en el proceso muy fuerte, y las historias se necesitan que sean parte de la vida de la gente, como que salgan de ahí, que emerjan de esas historias cotidianas, 
y la vida que pueda tener el video después, es muy importante, eso nos gusta mucho, y también nos gusta mucho ser cine lo que vamos creando, y para la ciudad creo que es un reconocimiento de una cosa que no sea tan - y estamos trabajando mucho en eso- de bueno y malo [...] en cambio nosotros como que buscamos una historia y esa es la historia de cada uno, y contarla, más allá de que sea buena o mala, más allá del escándalo, más allá de rescatar los valores. (Germán y Wicho, 24 de marzo de 2014, entrevistada por Molina, I., Medellín)

Esta es una postura específica frente a exaltar el morbo o lo bonito de la ciudad, por eso entre el grupo prevalece la idea de contar las historias como son, desde la vida misma. El uso alternativo de medios de comunicación como el audiovisual les permite introducir otros relatos frente a la cotidianidad de los hombres y mujeres de la periferia de Medellín, a reconocer otras formas de constituir lo común, de establecer vínculos, de construir o concebir el territorio con las complejas relaciones que se producen en él y que afectan positiva o negativamente a los habitantes del barrio o la comuna. La posibilidad de visibilizar estas prácticas y estos sentidos que subyacen y se modifican permanentemente en la cotidianidad devela actores, subjetividades, prácticas e imaginarios que se ignoran para la gente de la misma ciudad, lo que favorece la estigmatización, segregación y violencia hacia algunos sectores sociales.

Otra cosa que se hace evidente en este fragmento es justamente esa identificación de quiénes son y qué es lo que los diferencia de los otros (Teleantioquia y Telemedellín). Como se mencionó anteriormente, esta postura reflexiva de crear al antagonismo implica un reconocimiento de sí, de los alcances de su acción y de cuáles son los factores que generan oposición en relación con otros, con "otro" que en este caso tiene nombre y que produce unas prácticas particulares con las cuales definitivamente no hay sintonía, porque desconoce justamente lo que le interesa a este grupo, la importancia de lo cotidiano, de las historias que se producen en ese ámbito. Esto es fundamental para comprender quiénes somos y qué hacemos como sociedad. Otro imaginario al que se oponen es a la exaltación del paisa como modelo por seguir: 
Hay unos que estamos con un objetivo muy claro y es un objetivo anti paisa, estamos mamados de ese paisa verraco, de ese imaginario mamerto y ciertas cosas culturales que son montañas muy bravas de vencer, en los chicos, en uno mismo, y uno se da cuenta que la gente es muy cerrada, que hay cosas más allá de estas montañas, por ejemplo una de las ideas de cocina de guiones era preparar platillos diferentes de los que tradicionalmente comemos, entonces con sabores amargos, sabores picantes cuesta, y saltarse ciertas cosas pues, entonces creo que hemos hecho cositas [...] (Germán y Wicho, 24 de marzo de 2014, entrevistada por Molina, I., Medellín)

Es una oposición abierta a estereotipos culturales propios de la región, que mantienen unas formas conservadoras de pertenecer a esta ciudad y que excluye la diferencia, que estigmatiza e ignora otras manifestaciones de expresión que son determinantes para construir una sociedad abierta y para consolidar imaginarios o representaciones sociales sobre ser joven y hacer parte de una cultura diversa.

El chiste de lo antipaisa no es sólo un chiste, si hay que luchar como con maneras muy conservadoras de la ciudad, por ejemplo el machismo con las mujeres, que está tan introyectado en nosotros, en esa idea de que servimos pa' todo, en el tema de la temporalidad, pues en el paisa no está admitido el ocio, todo el tiempo trabaje, trabaje, y no, hay que vagar también, el rock es muy excluido aún, hay vetos contra los chicos, hay vetos contra todas esas maneras alternativas, y hay una cosificación de lo alternativo también, los medios se chupan muchas cosas aquí, y cosas muy alternativas las vuelven para la institucionalidad, entonces como que hay una pelea cultural de fondo muy tesa, ¡va de retro paisita! (Germán y Wicho, 24 de marzo de 2014, entrevistada por Molina, I., Medellín)

Esta oposición en los productos audiovisuales es una forma de antagonismo a ese imaginario instalado en la subjetividad de los habitantes de la ciudad y validado discursivamente en las prácticas sociales cotidianas de esta región de Colombia, de ahí la apuesta por enunciar o 
mostrar otro tipo de subjetividades, de miradas; otras formas de enunciar, de posicionarse desde un lugar diferente para nombrar la vida, para hacer evidentes dichos límites y tratar de sobrepasarlos.

Dicha oposición también es una forma diferente de nombrar realidades sin acudir a esa tendencia academicista de empaquetar realidades y sujetos en categorías universales que terminan encerrando y estereotipando nuevamente a los actores sociales. En este grupo también hay un distanciamiento y una crítica hacia el sistema académico que nombra o categoriza al sujeto, y que lo limita sin siquiera comprender a profundidad la densa red de relaciones en las que este se desenvuelve: “¿cómo uno puede generar categorías para analizar al otro cuando no lo conoce bien y no logra describir ni interpretar bien la realidad que el otro vive?" (Corporación Pasolini en Medellín, 15 de marzo de 2014, entrevistados por Molina, I., Medellín).

$$
* * *
$$

Como vemos, la postura antagónica que moviliza a estos grupos sobrepasa la dimensión amigo/enemigo, y se convierte en una condición indeterminada que es altamente productiva pues se configura reflexivamente como una oposición consciente, que posibilita reconocer o hacer visibles los límites, tanto identitarios, como normativos y discursivos, que denotan o caracterizan las relaciones descritas. Pensado así, el antagonismo se convierte en el dispositivo concreto para la acción, para provocar el florecimiento de lo político, empezando por el campo de lo discursivo y la significación.

La realidad que expresan los grupos consultados permite entender un poco más la idea de que el antagonismo permite hacer evidentes los límites de lo social, porque en las comunidades a las que pertenecen estos jóvenes existen unas prácticas sociales que se han instalado en la subjetividad, se han normalizado y establecen lo aceptable. Por ejemplo, que la violencia es una fuerza que ejercen unos cuantos y frente a la cual solo queda el sometimiento, el silencio o el miedo; o frente a la lógica de la modernidad hay que competir dejando de lado la solidaridad y el goce, u olvidar una relación más equitativa con la naturaleza como principio vital; o naturalizar la exclusión y la estigmatización de la diferencia como una expresión de la cultura y la tradición. 
En estos tres casos, la acción de estos grupos advierte que hay unas formas que la sociedad o las comunidades en las que existen han empleado para configurarse como tal, a partir de unas normas, unos roles y unas prácticas que son aceptadas por la mayoría; sin embargo, dichas prácticas no son tan saludables cuando se hace evidente que mantienen un orden social que desatiende la posibilidad de construir otras alternativas de convivencia, que limita la construcción de lo público, que impide la "aparición" de la diferencia y de otros discursos, que en aras del consenso social instala o legitima formas de exclusión que, entre otras cosas, descarta subjetividades como las de estos jóvenes que decidieron manifestarse a través de sus intereses personales y que han aprendido a mantener una actitud reflexiva en esa oposición y construcción discursiva del adversario.

Estos límites que establecen lo social implican exclusión, en el sentido de negar la diferencia, pues estos se establecieron justamente con el fin de homogenizar las prácticas, los discursos, las necesidades e instaurar un esquema u orden social que es coherente con el tipo de hombre que este sistema necesita; es decir, un ciudadano que responda a la lógica de la democracia liberal. En este proceso se reduce la posibilidad de problematizar o resignificar el mundo de la vida, porque es solo en el momento cuando se cuestionan los límites establecidos que se configuran otras posiciones de sujeto, otras subjetividades, otras posibilidades de socialización, de acción y discurso que permitan la aparición de lo político.

La política como intento de domesticar "lo político" de acorralar las fuerzas de la destrucción y de establecer el orden, siempre tiene que enfrentarse a los conflictos y antagonismos, esto nos obliga a entender que todo consenso está, por necesidad, basado en actos de exclusión y que nunca puede ser un consenso racional, completamente inclusivo. (Mouffe, 1993, p. 160)

Ahora, vale la pena tratar de establecer una distinción entre antagonismo y conflicto, porque si bien comparten elementos de oposición y los dos son procesos comunicativos, el antagonismo contiene una potencialidad abierta hacia la constitución de la diferencia que en el 
conflicto resulta limitada, por cuanto este se restringe al logro de unos intereses específicos que perfectamente pueden despolitizarse.

El conflicto es sinónimo de incertidumbre, lo cual reduce las posibilidades de predecir lo que en él o a partir de él se puede generar, básicamente porque es una entidad cambiante. Ante todo es un proceso comunicativo entre dos o más actores que tienen un interés compartido, pero la existencia del otro se convierte en impedimento u obstáculo para poder satisfacer dicho interés; así, los actores se convierten en opositores o incluso enemigos por un elemento en disputa. Como fruto de esta interacción, se genera una oposición específica entre los agentes participantes y se convierte en el detonante para una serie de acciones vinculadas a la obtención o satisfacción de dicho interés contrapuesto, que en algunos casos puede ser gestionado a partir de un tercero (mediador) para buscar una salida más o menos satisfactoria a dicho interés contrapuesto; en otras ocasiones se convierte en el detonante de salidas violentas que terminan ampliándolo o suprimiéndolo, cuando por ejemplo se elimina al adversario.

El antagonismo, por su parte, si bien devela una posición contradictoria entre actores, es ante todo una condición que permite establecer los límites entre el yo y el ellos, como un dispositivo que hace evidente las diferencias entre los agentes participantes. Es un ejercicio comunicativo que pasa por el proceso de reflexión por descubrir qué soy yo, cuál es mi identidad, para ubicarme como diferente, opositor u adversario (no necesariamente enemigo) frente a otro agente, como un relato paralelo que se produce a partir de un exterior constitutivo que hace explícitas unas condiciones particulares que caracterizan a los actores en oposición y que son determinantes en dicha relación antagónica. Además, estas diferencias que se enuncian y que son importantes en la interacción hacen que ese vínculo temporal o contingente produzca no solo interlocutores, sino también adversarios en relación, pues uno determina al otro como exterior constitutivo de la diferencia.

La idea de exterior constitutivo, ocupa un lugar decisivo en mi argumento, pues al indicar que la condición de existencia de toda identidad es la afirmación de una diferencia, la determinación de otro 
que le servirá de exterior, permite comprender la permanencia del antagonismo y sus condiciones de emergencia. (Mouffe, 1993, p. 15)

Las diferencias entre enemigo y adversario son fundamentales para entender lo político (Mouffe, 1993). La tesis de Mouffe refiere que el agonismo permite establecer adversarios y no solo enemigos, en el sentido en que al adversario se le construye en el proceso de la diferenciación de este como exterior constituyente de la identidad en disputa, del nosotros que se diferencia del ellos, no es un enemigo a abatir, sino que se legitima en su existencia, pero al cual se le confronta activamente. Yo entiendo que el antagonismo produce (en el sentido comunicativo de dotar de sentido el vínculo con alguien o con algo) adversarios, en cambio el conflicto produce también enemigos.

Para Laclau y Mouffe (2004) el antagonismo investido como una relación que potencia agenciamientos discursivos es fundamental en la constitución de lo político. Sin embargo, una de las características de los planteamientos de estos filósofos es la vinculación del concepto de lo político en una perspectiva de la hegemonía; es decir, que solo en la medida en que el antagonismo reúne a un grupo considerable de actores o de cadenas significantes puede establecer una irrupción tal que produce efectos dislocantes del orden establecido, y así amplía los límites de la significación y visibiliza o incorpora otras cadenas de significación que instituyen otros imaginarios y prácticas específicas.

Es decir, lo político tiene lugar en la medida en que se configura como un elemento dislocante del orden discursivo instituido. En este punto introduzco una fisura a este planteamiento, porque creo que el florecimiento de lo político no implica necesariamente una afectación en lo público de escalas regionales o nacionales, pensado en términos hegemónicos. Es decir, lo político como una movilización de lo social no depende del nivel de incidencia que produzca, porque de ser así solo los grandes movimientos sociales tendrían ese chance, y sabemos que en la vida cotidiana para que un movimiento social alcance este tipo de incidencia tiene que empezar por lo pequeño y por un proceso propio de evolución y crecimiento que también es contingente. Por ejemplo, el trabajo que adelantan estos grupos tiene sentido en la 
escala en la que se desarrolla, es decir, entre los participantes, sus familias y sus grupos cercanos de interacción, en algunos casos en el barrio o la comunidad. Sin embargo, no sobrepasa a una escala regional, y aun así son clave para movilizar agentes, para configurar modos de significación que irrumpen o se oponen a los imaginarios instituidos colectivamente, y que dotan de sentido las prácticas de los y las participantes; así activan procesos de creación, de subjetivación política y acciones específicas que dinamizan otras realidades, otros escenarios o procesos de argumentación, otras formas de incluirse o vincularse a lo público, de tener voz y ser significativo en comunidades específicas.

Para Laclau (2002) la relación de antagonismo tiene que dotarse de significación como práctica y tiene que activarse en el campo de lo discursivo como una desfijación de sentido que permite la irrupción y al mismo tiempo abre la posibilidad inédita de reinscripción, a partir de la cual se constituye lo político como apertura de lo social.

Esa posibilidad de reinscripción es importante destacarla como manifestación explícita de lo político en las experiencias analizadas. Como se mencionó anteriormente, el campo de acción o de dislocación de dicha reinscripción en el ámbito de lo público se limita al entorno inmediato donde se originan estas prácticas, condición que no deja de ser fundamental para el nivel de incidencia de estos jóvenes, en este caso en una escala inicial, donde no solo hacen explícita la oposición frente al consumo globalizado, por ejemplo, sino que resignifican este antagonismo en la escala en la que esta tiene sentido, es decir, en el campo de acción donde cada agente se desempeña. Esa resignificación solo se materializa en el discurso — sentido— y la acción — prácticacuando se reelabora reflexivamente y se hace explícita, en este caso, a través de las prácticas estéticas que desarrollan estos grupos.

Para ilustrar lo anterior, me ocuparé de analizar un ejemplo que + puede servir al despliegue del argumento referente a la enorme tarea que exige hacer explícito un antagonismo, y el reto que implica hacer ese ejercicio de reinscripción en lo social como desarrollo de lo político, es decir, de desfijar sentido.

Configurar un antagonismo es una tarea reflexiva compleja, pues no basta con enunciar una oposición; en términos comunicativos, exige más que una negación de algo, es una reflexión que pasa por la acción, 
que obliga a los implicados a producir nuevos sentidos. Por ejemplo, en el caso de los jóvenes desaparecidos de Ayotzinapa en México, ${ }^{8}$ la gran movilización que lideran diversos grupos sociales, especialmente jóvenes, está relacionada con el hecho de trazar una posición de indignación y rechazo a los hechos de la desaparición de los 43 normalistas en 2014; al hacer pública su molestia se busca exigir justicia ante el Estado. Esta es una oposición tajante que determina un rechazo, pero que no deja de ser un efecto de un hecho, es decir, no se sigue tramitando, se hace explícito el reclamo o la molestia y posiblemente con el paso del tiempo se olvidará o no pasará nada extraordinario en términos políticos, diferente a aumentar la desconfianza hacia las instituciones o es posible también que se logre configurar un movimiento social que propenda a la construcción de una agenda de nación que agrupe a los diversos actores sociales y que movilice transformaciones concretas.

Aún no se sabe cómo se tramitará, porque este conflicto irrumpe la dinámica cotidiana de una ciudad como el Distrito Federal, que afecta a más de 20 millones de habitantes, empezando nada más por las movilizaciones, por los paros en las instituciones educativas, por los daños en los bienes públicos o por la polarización de información que circuló en las noticias mexicanas durante el último trimestre de 2014. Aparte de estos hechos, que no dejan de ser significativos para la cotidianidad de la gente, no ha ocurrido el proceso de reinscripción social del acontecimiento, aún no se produce esa acción dislocante de la que habla Laclau (2002). Los hechos no han producido, más allá del estupor y la indignación de los mexicanos, una oportunidad concreta para modificar de fondo alguna práctica política o producir una reforma significativa en la manera como se produce la gobernabilidad, o algún cambio en reducir la desconfianza colectiva hacia los partidos y la política tradicional.

Este es un buen ejemplo para entender la complejidad que implica un antagonismo productivo socialmente. No obstante, también hay que entender que en este caso hay muchos agentes e intereses en juego,

8 Este ejemplo da cuenta del análisis del momento específico durante el segundo semestre de 2014. 
y que un acontecimiento como este - que moviliza a tanta gente- se convierte también en una ola de especulaciones y de intereses que es muy difícil coordinar y mantener en el tiempo, en gran medida porque se hace evidente a través de acciones espontáneas que atienden a la evanescencia de la movilización coyuntural de masas.

Configurar un antagonismo va más allá de enunciar un conflicto, porque implica una reflexión permanente frente a los intereses en juego; además, no responde necesariamente a una relación concreta entre agentes, sino que tiene lugar en el plano de lo imaginario, de lo intangible, pero que se inscribe en lo práctico. En este ejemplo, ese proceso de reinscripción en lo social se queda solo en la marcha, en manifestaciones multitudinarias que son tangibles mientras dura la marcha, pero no se materializa en ámbitos de discusión de la comunidad en general; se circunscribe a un tratamiento mediático y carece de significación en las prácticas cotidianas de la sociedad civil.

En contraposición, Uno entre mil es un grupo que permite comprender un poco mejor cómo el antagonismo es clave en su práctica, ya que no es una oposición o confrontación con un agente específico, pero todo el sentido del grupo se orienta en función del antagonismo hacia la sociedad globalizada que prevalece en el actual sistema capitalista. Aquí no hay un solo agente, los rostros de los adversarios son cambiantes, no son fijos, pero las reflexiones que median dicho antagonismo son permanentes entre los participantes del grupo, y permiten el florecimiento de acciones específicas.

Para Uno entre mil, la ritometodología no es solo una metodología, es tambien la materialización de esa apuesta colectiva, de sobrepasar este plano tangible y establecer otro tipo de conexiones con cada participante, con los otros y con el mundo. Es una forma de vida, que privilegia el ritualizar como la posibilidad de conectarse con el universo, de ordenar la vida y las prácticas cotidianas en función del propósito que cada quien mantiene.

No es ritualizar pues como irse al extremo también, sino uno poder desde que se levanta poder ordenar el pensamiento y ordenar la palabra y qué es lo que quiero para este día, qué me sirve para mi sueño diario, cada día la prioridad de ordenar, entonces 
la ritometodología es la forma en la que hemos construido las apariciones y las actividades de Uno entre mil, cómo desde el rito, desde ritualizarnos. Eso es tan potente que te ayuda a vos en lo que estás escuchando, digamos en el caso de una empresa, cuando empezamos un ktaller, cuando hemos llevado las apariciones en la Escuela de artes, cómo nos ritualizamos, cómo desde el inicio agradecemos, y cómo cuando finalizamos también agradecemos todo lo que nos llega, la ritometodología llega también a partir de lo importante que ha sido para nosotros ritualizar cada momento, entonces las apariciones y las actividades de Uno entre mil están ligadas a eso, todo tiene un orden y un orden que llega por el juego. (Julián y Natalia, 30 de marzo de 2014, entrevistados por Molina, I., Medellín)

Es la concreción del interés del grupo de hacer del juego una oportunidad para descubrir nuevos valores, pero también para aprender a conocer-se individual y grupalmente, pero de una forma consciente que implica la vinculación de lo sensible, del goce y la reflexividad, la cual se resume en el camino del Benjamín: "nosotros estamos develando una cosa fundamental, que aunque parece un juego, es muy serio y lo llamamos el camino del benjamín, pero es tan profunda que solo estar en este viaje que decidimos montar nosotros, ya" (Uno entre mil, 29 de marzo de 2014, entrevistados por Molina, I., Medellín). Acá reside la importancia de esta propuesta, de conciencia de cada participante en concordancia con el papel que desempeña en su mundo doméstico o cotidiano.

Lo anterior es un llamado profundamente humanista, porque apela a mantener despierta la esencia de lo humano, a sentir, al disfrute y a actuar en concordancia, olvidando o transformando eso que dijeron que era el mundo donde había que vivir. Es una apuesta profunda por el juego como la oportunidad de descubrir el objeto de poder de cada uno, o sea, el talento propio, y solo cuando se entiende la potencia de ese objeto de poder, es posible explotarlo, o sea, hacerlo realidad. A eso es a lo que Julián llama empoderarse, apropiarse de ese poder (el talento de cada uno) y lograr que a través de este cada uno brille y pueda convertirse en Benjamín, para que ilumine a otros también. Es 
un llamado a despertar frente a lo que mantiene dormidos o pasivos a los agentes y poder armar otra realidad, consciente.

Esta perspectiva es un reto, porque exige aprender a vivir con esa certeza en el corazón que da firmeza e impulso para cambiar y así transformar la vida de otros. Para eso, se valen de la lúdica patafísica, que busca generar otra realidad, más allá de la que este plano lineal donde nos posicionamos ofrece: "la patafísica es un manifiesto: cómo generar realidad más allá, alrededor de lo que estamos imaginando" (Uno entre mil, 29 de marzo de 2014, entrevistados por Molina, I., Medellín). La patafísica tiene que ver con las soluciones imaginarias y el estudio de las leyes que regulan las excepciones, porque "lo interesante es lo excepcional”.

Para el grupo, el cambio empieza inicialmente en cada agente, porque cada participante es su propia responsabilidad o tarea; si cada uno aprende a resolver ese asunto seguro podrá ayudar a cambiar otras realidades.

Es muy difícil, pero siempre he pensado que no es cómo cambio el sistema sino cómo cambio mi sistema, y cómo yo llego a mi sanación, mi sanación hace que el otro se sane, cuando yo descubro cosas tan potentes como las que hacemos en uno entre mil, y yo me la juego y yo me empodero, y efectivamente eso funciona en mi vida, y el otro se la pilla, surgen nuevas cosas. (Julián y Natalia, 30 de marzo de 2014, entrevistados por Molina, I., Medellín)

Este razonamiento parte de la influencia sutil que se puede generar en relación con el otro, pero el lugar inicial y privilegiado de acción siempre es uno mismo: su cuerpo, su subjetividad, su trabajo, y al movilizar transformaciones inicialmente en cada uno es viable pensar cómo al moverme voy afectando a otros. Se posibilita otra forma de acción, de visión, de vida. Para esto, el juego se convierte en el medio y el fin; el juego es la medicina, es la posibilidad de despertar lo que se había dormido en cada uno, a través del disfrute, del goce, de la alegría que produce la sorpresa y esta forma de compartir tan diferente a lo que socialmente se ha establecido como forma de interacción: la racionalidad y la materialidad. 
Me imagino que la Eskuela de Artes y ocupaciones felicitarias le permite ver eso a las personas y descubrir que hay otra forma de caminar diferente a la que nos han contado, que es una forma diferente de vivir nuestra vida, que uno nace, estudia, tiene su familia, tiene su casa, su carro, su gato sino que también hay otra forma de empoderarse, de ser un mago, para usted vivir bien bonita la vida, así me sueño yo la escuela, como que podamos nosotros tener eso nosotros tan clarito tan clarito, que le podamos brindar esa oportunidad a las personas, no llenándole el hueco ni peleando con nadie, sino diciéndole por medio de juegos, por medio del juego, que esa es otra cosa que yo me sueño con la escuela, que nosotros tengamos tan firme y tan potente lo que puede hacer el juego como medicina que vos de ahí hagás cacería, que vos de ahí te podás pillar muchas cosas que en lo que estamos atrapados, en la que cada uno está atrapado, juepucha que cuando yo juego esto cómo me puedo yo liberar y llegar a otro nivel, así me sueño la escuela..., es una cosa tesa pero yo creo que ahí vamos. (Julián y Natalia, 30 de marzo de 2014, entrevistados por Molina, I., Medellín)

Sin embargo, para Uno entre mil el juego no es un jugar despreocupado; tiene implícita una actitud reflexiva - metalúdica- en cada experiencia, no solo con la actitud para jugar, sino también para acatar y proponer reglas de juego, para transformar el entorno donde se movilizan, como un desafío permanente que la lúdica patagógica trae a los participantes. Es una forma de interacción que privilegia el disfrute, pero que tiene una intencionalidad reflexiva a partir de la actuación de cada uno y su interés en la vida, su genuino interés por ser o hacer lo que voluntariamente desea.

Este por ejemplo es uno de los propósitos latentes en el kraken de la Eskuela de Artes y Ocupaciones Felicitarias, que busca a partir de la relación con los niños aprender a ver cosas que ya no recordamos, pero también a trabajar con ellos, para que a través del juego se pueda interactuar y aprender.

Cómo encontramos en la manera de alumbrar a las personas, con los niños o con quien sea, y en ese compartir cada uno encuentra 
su propia realidad y encuentra respuestas de por dónde caminar, y eso es lo que a mí me parece muy mágico de la escuela de artes, todo lo que uno tiene al compartir con las personas al jugar y la potencia que tiene el juego. (Julián y Natalia, 30 de marzo de 2014, entrevistados por Molina, I., Medellín)

Lo que subyace a estos relatos es ante todo un agenciamiento discursivo que denota un ejercicio de reflexión y de construcción de sentido frente a unas prácticas específicas, las cuales son importantes para establecer un ámbito de acción individual y grupal que corresponde con el ideal de hombre al cual le apunta esta organización. Al hacer preeminente el interés por el juego como dispositivo que abre mundos de acción, estos jóvenes están enunciando que es posible dotar de sentido político una operación que convencionalmente no tiene ninguna vinculación con el ámbito de lo político; están haciendo uso del poder de enunciar una posibilidad de acción diferente a la establecida tradicionalmente en la democracia liberal. Al hacerlo, están reivindicando al juego como oportunidad de acción productiva socialmente, es decir, están posicionando discursivamente a esta forma "particular" de ser y hacer, visibilizándola con la enunciación, otorgándole audibilidad y sentido en su horizonte de proyección.

Esta es una apertura discursiva que permite la dislocación y reinscripción de las que habla Laclau. Al comprender la experiencia del grupo Uno entre mil, es posible señalar que para que tenga lugar lo político no se necesita precisamente una condición de movilización de masas o de inscribirse únicamente en la escala de lo hegemónico, para que un proceso cumpla con esa función disruptiva o dislocadora de lo instituido; por el contrario, se evidencia un proceso comunicativo de construcción de contenidos que están implícitos respecto a la estructura y sobre todo con las relaciones sociales, más como una condición de nicho, es decir, que se supedite a procesos reflexivos frente a lo social, tomando partido de la condición inacabada y dinámica de lo social, que desemboque en la resignificación de sentidos, que tengan impacto en el ámbito donde los agentes configuran su existencia en lo privado y en lo colectivo. En este caso, en sus propias existencias, en la relación que establecen entre ellos y con otros agentes de 
su comunidad, como grupo con otros, es decir, en el entramado de relaciones a las que se vinculan cotidianamente como organización. Es ahí donde lo político emerge, en la relación con los otros, en la posibilidad de configurar sentidos paralelos que designen y transformen el mundo de la vida de estos agentes, como partícipes activos de una comunidad, los cuales, a la larga, terminan modificando también las condiciones imaginarias que configuran lo social.

Para Laclau (2002), no basta con hacer explícita la oposición, sino que es necesario constituir discursivamente al antagonismo, porque es en el discurso donde se configura lo social, donde se pueden introducir rupturas de lenguaje que son definitivas al momento de resignificar conceptos o situaciones, para dotar nuevamente de sentido las prácticas sociales y los aprendizajes que en ellas se producen.

Constituir discursivamente al antagonismo o, en otras palabras, constituir al adversario, es un ejercicio que pasa por reconocer o ubicar los límites de lo social, los cuales se posicionan a partir de las identidades en juego y, en palabras de Laclau (2002), de las contradicciones profundas que subyacen a las equivalencias de lo social. Al problematizar discursivamente dichos límites, se produce necesariamente un develamiento de lo social, de los acuerdos o mínimos a partir de los cuales se establecen las prácticas y los sentidos aceptados colectivamente. Lo que sucede es que necesariamente estos acuerdos a partir de los cuales se constituye lo social siempre producen un margen de exclusión, sobre todo de la diferencia, y es ahí donde opera justamente la potencia de lo político, por cuanto se hacen evidentes los límites, se problematizan y se pueden modificar, es decir, se pueden resignificar, se pueden reincoporar a lo social de una forma diferente, para adaptarlo así a lo que el grupo espera o a lo que el sistema, contingentemente, determina. Esta es la dislocación que produce el antagonismo en las cadenas significantes, es el advenimiento de lo político a través del antagonismo.

Esto es lo que ha hecho Uno entre mil, cuando entiende como grupo que la manera más efectiva de problematizar su realidad es a través del juego, el juego como una oposición a la racionalidad argumentativa que impera en las relaciones sociales, el juego como detonante de talentos, de espacios de creación que fortalece vínculos y que genera diferentes posicionamientos frente a la academia, frente al trabajo, 
frente a lo público, frente a la relación con la naturaleza, frente a la potencialidad de lo humano.

Entender al antagonismo como una práctica que amplía los límites de lo social es fundamental para comprender la acción de los grupos analizados, en función de configurar al antagonismo como un ejercicio reflexivo de movilización y sobre todo de reelaboración permanente de lo social y de ellos mismos como grupo, a partir de las relaciones que establecen estos jóvenes, las cuales se reelaboran permanentemente. Es decir, se analizan y se resignifican en la práctica, no solo en el ejercicio de nombrarlas de otra forma, porque encuentran sentido en el mundo de la praxis cuando se inscriben en la experiencia estética que promueve cada grupo.

Cuando se hace explícita esa relación antagónica que moviliza al grupo, esta se convierte en una constelación reflexiva que promueve acciones concretas; constelación en el sentido de un agrupamiento de factores y percepciones, que en el caso de las experiencias analizadas se enuncia en singular: hacia la violencia, hacia el consumismo globalizado, hacia el imaginario de ser paisa, pero que incluye una densa trama de relaciones, de agentes, de motivaciones e intereses que subyacen a esa denominación y que son asumidos complejamente en las experiencias estéticas promovidas por estos agentes.

Esta dislocación discursiva está necesariamente articulada a una condición de contingencia, pues es la constitución de sentido la que está en juego en esa posibilidad del lenguaje, como un proceso no determinista y que depende de las relaciones sociales de los agentes, en la posición de sujetos vinculados a la estructura social a la que pertenecen y los regímenes de significación instituidos.

Dicha contingencia no es producto de condiciones azarosas o de accidentalidad, sino que las condiciones de un sistema son contingentes por cuanto no pueden ser derivadas de la lógica interna o de la racionalidad del sistema al que pertenecen; son indeterminadas en cuanto hay múltiples factores que influyen en la evolución o transformación de un proceso. Por eso entiendo que esa posibilidad de reinscripción de lo social, a partir de nuevos significantes que son fruto de la acción y el discurso de un agente o de un grupo determinado, está limitada necesariamente a las condiciones en las que se produce el discurso, en 
las que tiene sentido la acción, a ese universo de significación donde se inscriben las relaciones de estos jóvenes, los sentidos que le otorgan a su acción y el tipo de discurso que producen, dependiendo del régimen de significación al que apelan.

Es ahí donde reside la potencia de la dimensión estética, a la que apelan en su práctica discursiva como un régimen que privilegia lo sensible, la afectación recíproca entre agentes a partir de la posibilidad de crear o inventar mundos de acción y de significación que tienen sentido para unos jóvenes como los de Uno entre mil, quienes deciden cambiar el nombre con el que se designan individualmente, cuando enuncian los espacios de acción del grupo de una forma diferente al tradicional, cuando ubican su trabajo o incidencia en la comunidad desligándose del mundo de la política, pero actuando conscientemente en función de cambiar relaciones claves para modificar el entorno donde viven. Así, por ejemplo, privilegian la cooperación y la solidaridad en los intercambios que establecen entre ellos y con otros, así como la oportunidad de conocerse y establecer vínculos duraderos entre los participantes, y el hecho de fortalecerse como amigos antes de reunirse para explotar económicamente los talentos que posee cada participante.

Lo que se busca afirmar acá es que el trabajo que hacen estos grupos puede llevar a reinscribir en lo social otras prácticas ligadas a la condición juvenil, ligada a la forma como se produce lo público, o ligado al mundo de lo político, pero esto es un proceso que se va construyendo poco a poco, en la interacción, en la configuración de antagonismos productivos comunicativamente, en la gestión de prácticas y discursos que configuran universos de sentido para los participantes de estos grupos, para las comunidades beneficiadas, pero también para los entornos sociales donde se movilizan estos agentes.

Las relaciones antagónicas como manifestación de lo político permiten articular las formas objetivadas de lo social, otros límites o fronteras de lo enunciable, apelando a otros regímenes de significación como actos de institución, es decir, como un acontecimiento que se da gracias a la contingencia que disloca y reconfigura lo social, como proceso de visibilización y articulación de lógicas excluidas o ignoradas, a modo de contradicciones o equivalencias que acompañan los procesos de significación que dinamizan el mundo de lo social. 